$\begin{array}{ll} & \text { Etnográfica } \\ \text { etnográfica } & \text { Revista do Centro em Rede de Investigação em }\end{array}$

Antropologia

vol. $18(3) \mid 2014$

Vol. $18(3)$

\title{
Entre a agroecologia e a fumicultura: uma etnografia sobre trabalho na terra, cosmologias e pertencimentos entre camponeses pomeranos
}

Between agroecology and tobacco production: an ethnography of the work on land, cosmologies and belonging among Pomeranians peasants

\section{Maurício Schneider}

\section{(2) OpenEdition}

\section{Journals}

\section{Edição electrónica}

URL: https://journals.openedition.org/etnografica/3855

DOI: 10.4000/etnografica.3855

ISSN: 2182-2891

\section{Editora}

Centro em Rede de Investigação em Antropologia

\section{Edição impressa}

Data de publição: 1 outubro 2014

Paginação: 651-669

ISSN: 0873-6561

\section{Refêrencia eletrónica}

Maurício Schneider, «Entre a agroecologia e a fumicultura: uma etnografia sobre trabalho na terra, cosmologias e pertencimentos entre camponeses pomeranos», Etnográfica [Online], vol. 18 (3) | 2014, posto online no dia 09 outubro 2014, consultado o 10 fevereiro 2022. URL: http:// journals.openedition.org/etnografica/3855 ; DOI: https://doi.org/10.4000/etnografica.3855

\section{(c) (†) \&}

Etnográfica is licensed under a Creative Commons Attribution-NonCommercial 4.0 International License. 


\section{Entre a agroecologia e a fumicultura: uma etnografia sobre trabalho na terra, cosmologias e pertencimentos entre camponeses pomeranos}

\section{Maurício Schneider}

No mundo contemporâneo, o tema da alimentação "ecológica" tem sido cada vez mais discutido. Muitos estudos enfatizam aspectos técnicos e econômicos e colocam a produção agroecológica como oposta àquela convencional, que faz uso intensivo de agroquímicos. Este trabalho apresenta a trajetória de uma família de agricultores ecológicos - camponeses de origem pomerana - inseridos em uma comunidade em que a maior parte dos agricultores trabalha com a produção de fumo, em uma localidade rural do município de São Lourenço do Sul, no estado do Rio Grande do Sul, Brasil. A coleta de dados deu-se através de etnografia realizada ao longo do ano de 2012. A partir da atenção às diferenças, especificidades e peculiaridades da família que se constituiu em principal interlocutora da pesquisa, são identificados elementos de um substrato cultural comum, que conecta família e comunidade. A análise mostra, assim, que tradição, religiosidade, cosmologias e significados do trabalho na terra dão base, mais que a rupturas entre dois modelos de produção, a elos de ligação entre aqueles que os praticam.

PALAVRAS-CHAVE: campesinato, comunidade rural, sociabilidade, alimentação, tecnologia, família.

Between agroecology and tobacco production: an ethnography of the work on land, cosmologies and belonging among Pomeranians peasants - In the contemporary world, "ecological" food has been increasingly discussed. Several studies emphasize technical and economic aspects and consider agroecological production as opposed to conventional agriculture, which makes intensive use of agrochemicals. This paper presents the trajectory of a family of ecological farmers - peasants of Pomeranian origin - belonging to a community where the majority of farmers works with the production of tobacco in a rural locality in the town of São Lourenço do Sul, Rio Grande do Sul state, Brazil. Data collection took place through ethnography, performed along the year of 2012. From the attention to the differences, specificities and peculiarities of the family which constituted the main interlocutor of the research, elements of a common cultural substrate that connects family and community are identified. Thereby, the analysis shows that tradition, religion, cosmologies and meanings of work on land, more than creating divides between two production models, support the links between those who practice them. KEYWORDS: peasantry, rural community, sociability, feed, technology, family.

SCHNEIDER, Maurício (mauriciodschneider@gmail.com) - Programa de Pós-Graduação em Antropologia, Universidade Federal de Pelotas (PPGAnt - UFPel), Brasil. 


\begin{abstract}
"Aos olhos dos conterrâneos Menocchio era um homem, ao menos em parte, diferente dos outros. Mas essa singularidade tinha limites bem precisos: da cultura do próprio tempo e da própria classe não se sai a não ser para entrar no delírio e na ausência de comunicação. Assim como a língua, a cultura oferece ao indivíduo um horizonte de possibilidades latentes - uma jaula flexível e invisível dentro da qual se exercita a liberdade condicionada de cada um" (Ginzburg 2006: 20).
\end{abstract}

\title{
INTRODUÇÃO
}

O presente trabalho busca refletir sobre a relação entre visões de mundo e o trabalho na terra de camponeses pomeranos, bem como sobre os limites individuais e coletivos das visões de mundo e dos pertencimentos comunitários. ${ }^{1}$ A partir da observação da trajetória de uma família de camponeses de origem pomerana na região da Serra dos Tapes, no estado do Rio Grande do Sul, Brasil, procura-se discutir as razões que levaram esta família a adotar a produção agrícola de base ecológica, diferenciando-se da comunidade da qual faz parte. De igual modo, procura-se evidenciar as redes de relações dessa família nos âmbitos de parentesco, vizinhança e religião e os elementos que conformam seu pertencimento à comunidade.

Esta pesquisa está inserida em uma agenda mais ampla, levada a cabo pelo Grupo de Estudos e Pesquisas em Alimentação e Cultura (GEPAC), vinculado ao Laboratório de Estudos Agrários e Ambientais, da Universidade Federal de Pelotas (LEAA/UfPel). No que se refere à articulação com este estudo, são dois os projetos de pesquisa relacionados: "Cultura, patrimônio e segurança alimentar entre famílias rurais: etnografias de casos significativos" (CNPq 559565/2010-0) e "Saberes e sabores da colônia: modos de vida e patrimônio alimentar entre pomeranos no Brasil meridional” (FAPERGS 1018354/2010-6), ambos coordenados pela Prof. ${ }^{a}$ Dr. ${ }^{a}$ Renata Menasche.

O estudo aqui apresentado também foi realizado em articulação com o projeto de extensão "Construção participativa de sistemas agroflorestais sucessionais no território Sul, RS (Encosta da Serra do Sudeste)", coordenado pelo Dr. Joel Cardoso, pesquisador da Embrapa (Empresa Brasileira de Pesquisa Agropecuária). Esse último projeto teve por principal objetivo a implantação de SAF (Sistemas Agroflorestais) em propriedades de agricultores ecológicos. Entre as questões presentes no projeto, as dinâmicas sociais e

l Artigo elaborado a partir do trabalho de conclusão de curso apresentado ao curso de bacharelado em Antropologia da Universidade Federal de Pelotas (UFPel) em 2013. Ganhador do V Prêmio Lévi-Strauss, concedido pela Associação Brasileira de Antropologia (ABA) na modalidade de artigo. Orientado pela Professora Doutora Renata Menasche (UFPel) - a quem quero aqui registrar agradecimento mais que especial, não apenas por sua impecável orientação, mas, sobretudo, pela cumplicidade e devoção que dedicou a este trabalho; sem isto, nada seria possível. 
processos culturais das famílias envolvidas conformaram a parte que coube à equipe do GEPAC desenvolver.

Uma das famílias inseridas no projeto da Embrapa é a família Mühlemberg. Foi assim que cheguei até sua propriedade, no Butiá. Essa família e o entorno em que se insere representaram o foco principal desta pesquisa.

As iniciativas de pesquisa acima mencionadas têm sido desenvolvidas na região colonial do município de Pelotas e municípios vizinhos, delimitada pela Serra dos Tapes. Tais estudos situam-se na confluência entre as questões referentes à alimentação, consumo e campesinato, a partir de uma abordagem antropológica.

A região da Serra dos Tapes situa-se no sul do estado do Rio Grande do Sul, abrangendo, dentre outros, partes dos municípios de Canguçu, São Lourenço do Sul e Pelotas. Conforme apontam Salamoni e Waskievicz (2013), seguindo-se à presença indígena, a Serra dos Tapes foi ocupada primeiramente por escravos fugidos ou libertos das charqueadas e posteriormente por imigrantes europeus não ibéricos, sobretudo alemães, pomeranos, italianos e franceses. ${ }^{2} \mathrm{O}$ processo de colonização teve início em 1848, incentivado pelo governo imperial e executado por iniciativas deste, do governo provincial e particulares. Assim, ao longo de toda a região da Serra dos Tapes, famílias de imigrantes de diferentes origens foram assentadas em pequenas propriedades policultoras, que, juntamente com os afrodescendentes, conformam hoje um mosaico étnico.

Hoje em dia, na paisagem da Serra dos Tapes é grande a presença de plantações de fumo. Muitas famílias de colonos aderiram à fumicultura, parte delas continuando a produzir alimentos, em boa medida praticando a chamada agricultura "convencional" - caracterizada pela utilização de insumos químicos e ausência de restrições às sementes transgênicas. Mas outra parcela optou pela agricultura de base ecológica. Como bem identificou Patrícia Pinheiro (2010), para muitos pesquisadores e técnicos agrícolas, os dois tipos de práticas - agricultura ecológica e fumicultura - são colocados em polos opostos, um deles primando pela saúde de produtores e consumidores, pelo respeito à terra e à natureza; o outro visando apenas o lucro, sem preocupar-se com valores de sustentabilidade.

Contudo, as duas formas de trabalhar a terra podem não estar tão dissociadas como supõem - ou talvez desejem - alguns. No cotidiano dessas famílias, ao contrário, pode-se perceber que essas duas maneiras do fazer agrícola coexistem, muitas vezes em uma mesma propriedade. Para ilustrar essa coexistência, basta observar que, em uma rede de vizinhança e parentesco, fumicultores

2 A Pomerânia era uma região da Europa, próxima ao mar Báltico, que esteve sob o domínio da Prússia até a instituição do Império Alemão, quando teve seu território dividido entre os domínios da Alemanha e da Polônia. No Brasil, além da colônia de São Lourenço do Sul, Santa Catarina e Espírito Santo também receberam imigrantes oriundos da Pomerânia. 
compram alimentos de produtores ecológicos e esses, por vezes, os auxiliam no trabalho com fumo - situação particularmente comum em contextos de adversidades climáticas, que demandam ação rápida e trabalho intenso. Ocorre, ainda, que em uma mesma propriedade conjuguem-se produção ecológica de alimentos e produção de "fumo orgânico".

Nesse quadro, o presente estudo vem apresentar e discutir os resultados de pesquisa etnográfica realizada em duas localidades rurais inseridas na região da Serra dos Tapes, município de São Lourenço do Sul: Butiá e Coxilha Negra. Trata-se de um contexto em que uma única família de agricultores ecológicos convive com uma vizinhança que é, em sua quase totalidade, produtora de fumo. As relações com as redes de parentesco e de vizinhança, a participação na congregação religiosa - Igreja Luterana - e o pertencimento étnico a que se vinculam - "colonos pomeranos" - orientam muitas de suas práticas, valores e visões de mundo e os aproximam, mais do que afastam, dos produtores que seguem outros modelos de trabalho na terra.

Entende-se a família Mühlemberg não como "representativa" dos agricultores de sua localidade, ainda que sua trajetória possa auxiliar a entender questões que perpassam contextos mais amplos. Tal qual a trajetória de Menocchio, personagem de Carlo Ginzburg (2006), tentou-se pensar a trajetória da família Mühlemberg em relação ao seu entorno. Pode-se dizer que tanto a trajetória de Menocchio quanto a dos Mühlemberg, mesmo com suas idiossincrasias em relação a seus conterrâneos e contemporâneos, tornam-se reveladoras do contexto de uma região e de uma época.

Em O Queijo e os Vermes, Ginzburg (2006) reconstrói a história de Domenico Scandella, o Menocchio, um moleiro que viveu na região do Friuli, Itália, no século XVI, à época da Inquisição. Menocchio tinha pensamentos muito particulares acerca da religião e dos dogmas da Igreja. Suas ideias desagradaram ao Santo Ofício, que o prendeu e o sentenciou à morte. Conforme observa Ginzburg, as ideias de Menocchio tinham origem em parte nos livros a que teve acesso, mas em parte ao próprio contexto cultural em que estava inserido. Segundo ele, mesmo um caso limite, como o de Menocchio, pode se revelar representativo de um contexto, seja negativamente, porque precisa os padrões estatisticamente mais frequentes, seja positivamente, porque permite evidenciar como a cultura popular age diferentemente sobre os indivíduos.

A inserção em campo realizou-se, sobretudo, junto à família Mühlemberg, acompanhando sua rotina no trabalho e na vida na propriedade. Também visitei e entrevistei outras famílias das localidades de Butiá e Coxilha Negra, a maior parte delas dedicada à produção de fumo, e participei de festas da Comunidade Luterana Menino Jesus de Butiá. Com o objetivo de abordar mais adequadamente a trajetória da família, além da etnografia, o trabalho de campo esteve baseado em parte na metodologia da história oral. Segundo Meihy e Holanda, a história oral "recorre à memória como fonte principal que 
a subsidia e alimenta as narrativas"; é o "passado espelhado no presente [que] reproduz, através de narrativas, a dinâmica da vida pessoal em conexão com procedimentos coletivos" (2007: 16).

Ainda, é preciso notar que neste estudo se fez uma opção por manter os nomes próprios dos interlocutores. Como demonstrado por Claudia Fonseca (2008), a questão do uso ou não do anonimato no texto etnográfico suscita inúmeras controvérsias entre os pesquisadores, estando relacionada com dilemas de caráter ético e político. Entendeu-se que colocar os interlocutores no anonimato não faria diferença em suas vidas, em parte porque já participaram de inúmeras outras pesquisas e em parte porque, por suas particularidades, tornam-se facilmente identificáveis.

\section{A FAMÍLIA E SUAS VISÕES DE MUNDO}

Seu Roni e Dona Lúcia Mühlemberg são casados há quase 40 anos e há 35 moram nesta propriedade, no Butiá. São pais de Luciano e Moacir, este último casado com Lucimara. A propriedade em que vivem, a maior parte Seu Roni recebeu em herança de seu pai. Quando faleceu, o pai de Seu Roni deixou duas porções de terra para os filhos. A propriedade em que a família vivia, de 38 hectares (em uma localidade próxima ao Butiá), ficou para o filho mais velho - o qual também se tornou responsável por cuidar os pais quando chegaram à velhice. A outra porção de terra (que originalmente pertencia à família da mãe de Seu Roni), de 50 hectares, foi dividida entre Seu Roni e sua irmã. Mais tarde, Seu Roni comprou outros 10 hectares, totalizando os 35 hectares que conformam a propriedade em que hoje trabalha com a família.

Luciano, o filho o mais velho do casal, tem 35 anos e é solteiro. É apelidado pelos familiares de "inventor" ou "cientista". Adora ciência e tecnologia, como sempre faz questão de dizer. É formado como técnico em agroecologia e já trabalhou em algumas cooperativas da região. Atualmente, Luciano está terminando a graduação em Automação Industrial. Luciano revela o desejo de permanecer vivendo no interior. Pretende utilizar o conhecimento que tem adquirido para ajudar sua família a aumentar a renda que obtém da agricultura, contribuindo para viabilizar que se mantenham na agroecologia, bem como para incentivar que outros colonos adotem esse sistema de produção.

Moacir, o filho mais novo, é bastante diferente de Luciano. Tem 27 anos e é casado. Moacir é apelidado de "capitão", uma referência a seu ímpeto no trabalho na terra. Ele nunca gostou de estudar e logo que pôde saiu da escola. O que realmente lhe traz satisfação é o trabalho na propriedade e o pensamento que, a partir dele, poderá um dia prosperar financeiramente.

Moacir e Lucimara moram na casa de Seu Roni. Explicam que isso é muito comum na região, já que os casais novos, em geral, não têm dinheiro para comprar outra propriedade. Eles, no entanto, estão inscritos no programa "Minha 
casa, minha vida". ${ }^{3}$ Têm por objetivo construir outra casa para eles na propriedade da família, que, após a morte do pai, provavelmente será dividida entre os dois irmãos.

Os Mühlemberg são produtores agroecológicos, os únicos da localidade onde moram. Faz mais de 18 anos que eles adotaram esse tipo de produção, após Seu Roni ter tido problemas de saúde em decorrência do uso de agrotóxicos. Nos 35 hectares de sua propriedade, eles cultivam uma produção bastante variada. Entre os produtos estão milho, feijão, soja, batata, batata-doce, mandioca, cenoura, beterraba, amendoim, além de frutas e hortaliças.

A maior parte desses produtos é vendida na "feira do produtor", que ocorre semanalmente, aos sábados, na cidade de São Lourenço do Sul. Deve-se acrescentar que, na feira, os Mühlemberg são também os únicos a vender produtos agroecológicos, enquanto todos os outros agricultores comercializam produtos convencionais. Parte da produção também serve ao autoconsumo da família e outra parte é destinada à alimentação dos animais.

A família é aqui entendida também como unidade de produção agrícola. Como aponta Klaas Woortmann (1990), "nas culturas camponesas, não se pensa a terra sem pensar a família e o trabalho, assim como não se pensa o trabalho sem pensar a terra e a família". E é o patriarca, ou "pai-patrão" (para os sitiantes de Sergipe estudados por Woortmann e Woortmann 1997), aquele que governa o trabalho da família. "O pai de família é como o 'dono' do saber, componente da hierarquia familiar" (Woortmann e Woortmann 1997: 38-39).

Desde que se casou e começou a trabalhar por conta própria na agricultura, Seu Roni utilizara agrotóxicos. Chegou mesmo a empregar muito "veneno", como conta. No entanto, com o tempo, foi adquirindo feridas na pele (principalmente pés e pernas), que não cicatrizavam, além de sentir mal-estar, enjoos e ânsia de vômito; problemas causados, segundo acredita, pelo uso de agrotóxicos. As narrativas de intoxicação são bastante frequentes entre os produtores que, nesta região, aderiram à agroecologia (Pinheiro 2010). Foi assim que Seu Roni e sua família tornaram-se produtores agroecológicos.

No início, ele integrava um grupo de produtores ecológicos que reunia mais 11 produtores do município. Com o tempo, entretanto, foram crescendo as dificuldades em obter rendimento satisfatório a partir desse modelo de produção. Foi assim que todos, à exceção de Seu Roni, abandonaram a proposta e saíram do grupo, deixando de produzir de forma agroecológica, retornando à agricultura dita "convencional" ou mesmo aderindo à produção de fumo, em que é particularmente intenso o uso de agroquímicos.

Seu Roni lamenta, dizendo que não está fácil continuar na agroecologia. Parte de sua produção, que antes era adquirida pela Coopar (Cooperativa 
Mista dos Pequenos Agricultores da Região Sul), hoje já não tem escoamento. A batata, por exemplo, "já está criando brote no galpão", lastima ele. Segundo Costa (1984), São Lourenço do Sul já foi o principal produtor de batatas do Brasil, chegando a exportar, na década de 1960, para diversas regiões do país e do exterior, como Uruguai e Argentina. Entretanto, agora a batata é produzida em larga escala - e com agrotóxicos -, pelos "grandes" (produtores), no Paraná e em São Paulo, chegando aos consumidores locais a preço bastante inferior, além de apresentar aparência mais "bonita" que aquelas produzidas sem agrotóxicos.

$\mathrm{Na}$ feira, o que se vende ainda é pouco. A concorrência com os supermercados e com os demais feirantes é grande. Os supermercados compram alimentos vindos de outros lugares e produzidos em larga escala, vendendo-os a preços bem mais baixos que os daqueles produzidos localmente. Ainda, para atrair fregueses, às vezes os supermercados colocam preços quase mais baixos do que o valor que pagaram pela mercadoria, diz Seu Roni. Para ter alguma chance de venda, lado a lado com os outros feirantes (produtores convencionais), ele nunca eleva seus preços muito além do que os outros pedem, mesmo sabendo que, no modelo em que produz, tem muito mais trabalho.

Atualmente, na propriedade de Seu Roni, está sendo implementada uma área de SAF. Cercou-se um terreno de $10 \mathrm{~m}$ x $10 \mathrm{~m}$ (para proteger dos animais) e lá, com o acompanhamento da Embrapa, foram inicialmente plantadas espécies frutíferas (laranjeira, bergamoteira), milho e adubação verde (mucuna, feijão miúdo, entre outros). O projeto consiste em, uma vez crescidas um pouco as frutíferas e derrubada a adubação verde, plantar outras espécies. Dando certo, o objetivo é ter cultivados alimentos para o autoconsumo e para a venda na feira.

As plantas estão crescendo. Seu Roni realiza o manejo periodicamente. Contudo, ele ainda se encontra um tanto cético em relação aos resultados que este sistema poderá trazer. Por enquanto, rejeita categoricamente a opção de implementá-lo no restante da propriedade e tem certeza que seus vizinhos, que em sua maioria lidam com a produção de fumo, dificilmente permitirão que se implemente em suas propriedades área semelhante.

Para Seu Roni e demais colonos da região, o ideal de cultivar a terra é drasticamente oposto àquele proposto pelos idealizadores dos SAF. Desde que seus primeiros antepassados estabeleceram-se nas colônias, entenderam que para criar uma lavoura precisavam limpar todo o terreno e plantar os cultivos em carreiras (linhas retas). O SAF, com os cultivos concentrados em pequenos espaços, transmite a eles certa ideia de "plantar no meio do mato", de descuido, "relaxamento". Mesmo para Seu Roni, que se preocupa em realizar uma agricultura que não agrida tanto a natureza - o que poderia aproximá-lo da proposta do SAF -, a presença de outras concepções acaba por afastá-lo do modelo implantado. 
Seu Roni, entretanto, sente-se pouco à vontade para abandonar o projeto iniciado pela Embrapa. Outros projetos da mesma instituição também são desenvolvidos em sua propriedade, introduzindo cultivares para experimentos e sugestões de técnicas de manejo. A relação com o pesquisador da Embrapa já vem de longa data. Por meio dela, Seu Roni e Dona Lúcia já puderam viajar para eventos e para conhecer propriedades de agricultores ecológicos de outros municípios do estado e de outras regiões do país. Nesse sentido, embora não concordem com o projeto, a relação de reciprocidade com o pesquisador da Embrapa os impede de rejeitá-lo.

Como demonstraram Woortmann e Woortmann (1997), o trabalho na terra envolve cálculos, com o objetivo de minimizar riscos. "O desperdício de trabalho, de tempo, de terra e de sementes contraria frontalmente a ética camponesa. Poupar recursos é componente central de todo o cálculo da sua produção" (Woortmann e Woortmann 1997: 56). Nesse sentido, "o cultivo, visto como um cálculo, implica um conjunto de fatores. De um lado, os macrossociológicos, determinados pelas transformações da estrutura agrária da região e das condições de acesso à terra [...]. Por outro lado, as condições de cultivo dependem ainda do ciclo de desenvolvimento do grupo doméstico" (Woortmann e Woortmann 1997: 127-128).

Na lida cotidiana na propriedade, o trio Seu Roni, Moacir e Lucimara quase sempre trabalha junto. Luciano, como já dito, estuda e trabalha fora de casa. Quando ele está na propriedade, entretanto, também ajuda na lavoura ou em outras tarefas. Dona Lúcia é responsável pela casa e pela comida, no que também é ajudada por Lucimara, que volta da roça antes do horário das refeições. Dona Lúcia também trabalha na lavoura, em tarefas que necessitem da ajuda de mais uma pessoa, como na capina dos "inços", na colheita de alguns produtos e no cuidado da horta.

Woortmann e Woortmann (1997: 135) comentam como, no mundo camponês, o trabalho constrói também as relações entre homens e mulheres. Assim que "o processo de trabalho, visto como processo ritual, constrói o gênero". Entre os sitiantes sergipanos por eles estudados, enquanto à mulher cabe voltar-se para dentro - a casa -, ao homem é reservado o mundo lá fora, desde a lavoura, externa à casa, passando pela feira, até o próprio mundo, de forma geral.

Na propriedade, quase tudo que é consumido na alimentação é produzido pela família. Além das frutas, vegetais, hortaliças e temperos (bem como alguns chás, que também são cultivados na horta), a família tem uma pequena criação de animais para "o gasto". Criam galinhas, porcos e vacas - na realidade, uma vaca (da qual tiram o leite que consomem), uma terneira e três bois. A vaca e a terneira foram presentes dos pais de Lucimara, por ocasião do casamento dela com Moacir. O esterco do gado também é aproveitado como adubação, depois de servir de alimento para as minhocas. Parece que a família busca seguir o que 
Woortmann e Woortmann (1997) denominaram de "princípio de internalização dos recursos da propriedade".

A prática da família na agroecologia, segundo justifica Seu Roni, ocorre por vários motivos, entre eles o cuidado com a saúde, como já foi dito. Percebe-se, além disso, que outros fatores também orientam essa escolha. É o caso do que diz respeito a visões de mundo.

Assim como os sitiantes sergipanos observados pelos Woortmann, Seu Roni acredita que a terra é dada por Deus para os homens trabalharem. A relação com a terra envolve, assim, respeito e reciprocidade, não uma atitude de exploração máxima. Com isso, torna-se moralmente errado "envenená-la" com o uso de agrotóxicos. Em seu modo de ver, o uso de agrotóxicos - assim como também os transgênicos - causa prejuízos à terra, além de danos à saúde daqueles que utilizam o "veneno" e dos que consomem os alimentos. Ele diz que modificar a natureza desse modo, pela mão do homem, não pode ser da vontade de Deus.

Seu Roni busca na Bíblia a fonte de muitas de suas conviç̧ões. Para ele, a mudança de tempos, anunciada no livro sagrado, já está a se observar. As mortes em massa e as tragédias que diariamente estão presentes nas notícias seriam provas do desrespeito à natureza - "natureza de Deus". Ele relembra uma passagem bíblica, segundo ele, que diz que "no dia em que o homem começar a roubar à terra, o mundo se transformará para pior". Para Seu Roni esse tempo já começou.

Conforme aponta Carlos Rodrigues Brandão (1986), há entre os grupos camponeses, independentemente da religião oficial a que se filiem, um padrão de religiosidade popular mais voltado para a vida cotidiana, o trabalho na terra e com fronteiras pouco precisas entre magia e religião propriamente dita. Joana Bahia (2011), a partir de estudo na região serrana do Espírito Santo no final da década de 1990, observa que os camponeses pomeranos costumam ter uma visão particular da religião luterana, que não necessariamente é idêntica àquela oficial, pregada pelo pastor, mas sim mais associada com a vida cotidiana, no campo. Costumam crer e executar diversas práticas de caráter mágico-religioso, que muitas vezes entram em conflito com a autoridade religiosa.

Segundo Woortmann e Woortmann (1997: 132), “o prático e o simbólico se fundem no processo de trabalho".

"O saber mágico e as crenças religiosas, para os trobriandeses, tanto quanto para os sitiantes (benzer o pasto e o gado ou recorrer aos santos, por exemplo), são tão necessários quanto o saber 'técnico', e conhecê-los é fundamental para que o antropólogo possa dar sentido ao esforço produtivo" (Woortmann e Woortmann 1997: 15). ${ }^{4}$

4 Malinowski descreve as práticas e crenças dos nativos das ilhas Trobriand em suas etnografias pioneiras (cf. Malinowski 1978 [1922]). 
Woortmann e Woortmann ainda complementam: muito além da técnica, "o processo de preparo da terra, como um todo, também envolve uma dimensão mágico-religiosa: frills, como diria Leach" (1965 apud Woortmann e Woortmann 1997: 60). Para Leach, "o processo de trabalho, além de suas dimensões técnicas, possui também seus frills e decorations. São eles que fazem do trabalho Kachin um trabalho Kachin, e o mesmo pode ser dito com relação aos sitiantes que estudamos" (Woortmann e Woortmann 1997: 134). Desse modo, "a prática da lavoura é informada por um modelo cosmológico" (Woortmann e Woortmann 1997: 166).

Para Seu Roni, os agricultores que não se preocupam com isso "não têm fé". "Não se importam se aquele alimento que eles vão vender fará mal para as pessoas da cidade, até mesmo para as criancinhas; dizem que se os consumidores da cidade também não se preocupam deve ser porque é isso mesmo que eles querem". Em outra ocasião, em conversa com Patrícia Pinheiro (2010: 144), Seu Roni comentou:

"Tu pode ver, muito colono planta batata-inglesa, mas ele não come. Mas então ele sabe que faz mal [aplicar agroquímicos]. Então é confiança. Mas aquelas pessoas que moram na cidade [que consomem], também são humanas. Se nós [agricultores] não temos coragem de comer aquilo ali, imagina [os outros]. Todo colono que planta batata-inglesa, ele sempre plantava uma lavourinha separada para ele comer. Então por que ele faz isso? Então ele sabe tão bem quanto nós que isso faz mal."

O respeito à natureza, para Seu Roni, vai além da lavoura. Na propriedade, tenta sempre manter uma ou mais áreas de mato, enquanto os outros colonos, como ele diz, já derrubaram tudo. Seu Roni conta que alguns vizinhos até já se ofereceram para comprar a madeira que resultaria da derrubada de suas áreas de mato. Mas ele sempre se recusa a fazer isso. Ele entende que não pode só tirar da terra, "tem que manter um pouco de mato para ela não enfraquecer demais".

Por fim, é preciso dizer que, além das concepções de fundo religioso, compartilhadas em maior ou menor grau com os demais membros da comunidade religiosa, outras correntes de pensamento também orientam o caminho da família pela agroecologia. É o caso de ansiedades presentes no mundo contemporâneo, como as questões de cunho ambiental, mudanças climáticas, aquecimento global, sempre citadas nas conversas com eles. Pode-se sugerir, nesse sentido, que os diferentes elementos presentes na visão de mundo da família têm origem nas diferentes redes de relações a que ela encontra-se filiada, como 
procura-se mostrar mais à frente. Na terminologia de Bruno Latour (1994), se trataria, por um lado, de "redes longas", com atores de diferentes contextos ligados ao movimento agroecológico e, por outro, de "redes curtas", como as de parentesco, vizinhança e religião.

\section{ENTRE O INDIVIDUAL E O COLETIVO: RUPTURAS E CONTINUIDADES}

Nas localidades de Butiá e Coxilha Negra há grande presença de famílias de origem alemã e pomerana e de famílias afrodescendentes. Em menor proporção, há também algumas famílias de "brasileiros" (designação para os colonos que não descendem de origem étnica europeia). A maioria dos pomeranos pertence à religião luterana, já os afrodescendentes e brasileiros são católicos. Nas festas, os membros de ambas as comunidades se misturam: católicos participam de festas luteranas e luteranos das festas católicas.

Segundo relatam, as pomeranas, com certa frequência, se casam com brasileiros, mas os homens pomeranos são desaconselhados a se casar com mulheres brasileiras. Uma vez que é a mulher, na cultura pomerana, a responsável pela manutenção das tradições, se ela integra o casal está assegurada a continuidade, ao contrário do que ocorre quando a mulher é de outra origem étnica. Não se fala de casos de casamento entre afrodescendentes e pomeranos. Os afrodescendentes são, em geral, mais empobrecidos que os demais. Alguns trabalham com sua própria plantação de fumo, outros trabalham como diaristas para os colonos. Os pomeranos dizem que, "apesar de a maioria ser gente muito boa, não gostam muito de trabalhar e por isso não prosperam”. Parece haver aí, claramente, duas concepções de trabalho muito distintas. A dos colonos pomeranos, atrelada a toda uma ética da igreja luterana, de "trabalhar de sol a sol", e outra dos afrodescendentes, carregada, possivelmente, desde os tempos da escravidão.

Hoje em dia, a grande maioria dos produtores tem como principal atividade econômica o cultivo de fumo. Quase todos explicam sua entrada e permanência na fumicultura pela impossibilidade de praticar outra atividade. A família Oswald, por exemplo, produzia leite, enquanto que os Bork vendiam alimentos para o "caminhão", que recolhia a produção para vender na cidade. Contudo, com o tempo, a renda que obtinham nessas atividades deixou de suprir suas necessidades.

Para o autoconsumo, algumas dessas famílias criam gado de leite, animais para carne (porcos, galinhas, reses) e plantam, principalmente, milho e feijão, além de cultivarem hortas. Alguns não empregam qualquer tipo de agrotóxico nesses cultivos, mas a maior parte desses camponeses os utiliza. Entretanto, muitos precisam comprar os alimentos que não produzem. A maioria opta por comprar nos armazéns na colônia ou vai ao mercado, na cidade. Alguns vizinhos compravam alimentos de Seu Roni (diziam que a produção ecológica era 
mais saudável), principalmente batatas, mas pararam de fazê-lo, em razão de os preços no mercado estarem mais baixos.

Os Mühlemberg parecem ser vistos pela comunidade com certa ambiguidade. Se, por um lado, essas famílias, mesmo trabalhando com a produção de fumo, avaliam em seus discursos que a produção ecológica é mais saudável para as pessoas e melhor para a terra; por outro, olham com certa desconfiança para o trabalho da família Mühlemberg. Seu Roni conta que em muitos momentos já foi chamado de louco e que seu trabalho foi posto em dúvida inúmeras vezes: "Diziam que isto não daria certo, que era loucura".

Além da convivência na rede de vizinhança com produtores de fumo - que fazem parte da mesma comunidade religiosa que a família Mühlemberg -, a fumicultura também está presente no interior de sua rede de parentesco. Alguns membros da família extensa, como o irmão de Dona Lúcia, são produtores de fumo. No último inverno, após uma forte chuva de granizo, o irmão de Dona Lúcia, cunhado de Seu Roni, perdeu quase toda a plantação. Seu Roni e os dois filhos abandonaram um dia de trabalho em sua propriedade para ajudar, junto com outros parentes, o cunhado a recolher o que sobrara.

É preciso notar ainda que, não obstante as concepções bem formadas e as eventuais críticas aos demais agricultores, ditos convencionais, Seu Roni não considera que todos devam adotar o modo de produção agroecológico - fato que, à primeira vista, parece um tanto curioso. Ele entende que não há espaço para todos nesse modelo. A feira não comportaria mais produtores vendendo alimentos e não haveria, a seu ver, outro meio de absorver essa produção. Embora algumas vezes critique, em outros momentos ele reconhece que mesmo aqueles que trabalham com o fumo atualmente não teriam outra opção. Preocupa-se, inclusive, com as legislações que visam extinguir essa atividade até $2020 .^{6}$

Anteriormente, Patrícia Pinheiro havia apontado relação, nesta região, entre a produção de base ecológica e a de fumo:

"Outro exemplo de complexidade da agricultura de base ecológica está em sua relação com o cultivo de tabaco. Convivendo com certa proximidade, por estar relacionado diretamente com a agricultura familiar, esse cultivo está presente em muitas propriedades que também mantêm cultivos de base ecológica" (2010: 168).

Ainda como observado pela autora, embora agroecologia e produção de fumo sejam comumente identificadas como pertencentes a polos opostos, para a maior parte dos agricultores essas práticas não são percebidas como 
tão distantes, sendo inclusive encontráveis em uma mesma propriedade: "A agricultura de base ecológica é constantemente situada como contraponto ao fumo - são produções consideradas pelos mediadores como conflitantes -, porém nas propriedades da rede a presença de um não necessariamente exclui o outro" (Pinheiro 2010: 147).

Se, por uma perspectiva técnica e econômica, as produções de fumo e agroecológica se situam bem distanciadas, de outra perspectiva, pensando as relações de vizinhança e de parentesco, elas não estão tão distantes assim. Valores associados à ecologia e à sustentabilidade são, dessa forma, conjugados pela família juntamente com outros valores, oriundos das relações comunitárias, da rede de vizinhança e parentesco.

Se o trabalho na terra a partir da agroecologia diferencia a família Mühlemberg da maior parte dos membros da comunidade - o que pode, de algum modo, afastá-los da vizinhança -, as festas podem ser percebidas como ocasiões de reencontro.

A festa é tomada aqui como lócus privilegiado de observação das relações sociais, uma vez que é entendida como "expressão dos valores da sociedade", tal como proposto por Menasche e Wedig (s.d., no prelo). Refletindo sobre as relações entre campo e cidade, essas autoras resgatam o clássico estudo de Bourdieu (2006), que analisa o baile camponês na região francesa do Béarn dos anos 1960, para pensar sobre as festas por elas observadas entre colonos alemães na região gaúcha do Vale do Taquari.

A família Mühlemberg, bem como as de muitos de seus vizinhos, é associada à comunidade luterana Menino Jesus de Butiá. Tal como é costume em outras comunidades luteranas da região, uma vez por ano - em setembro é organizada uma festa em que são recebidos visitantes vindos de outras localidades, assim como da cidade. Existe uma espécie de circuito de festas. A cada domingo acontece uma festa em alguma comunidade do município ou de municípios vizinhos. Na ocasião, as demais comunidades dirigem-se ao local para prestigiar a iniciativa. A família Mühlemberg, junto com outros membros de sua comunidade, participa de festas em quase todos os fins de semana.

No Butiá, a festa tem início com o culto na igreja, seguido de almoço - buffet com churrasco, saladas, pães, cucas - e, à tarde, baile com banda "estilo alemão" (para os mais velhos). Durante a tarde também ocorrem sorteios de rifas e jogos, na parte externa do salão. À noite, os jovens confraternizam em outro baile, esse com música de discoteca.

A festa da comunidade Menino Jesus tem por tradição servir, dentre outros pratos, uma sopa de galinha e um caldo preparado com carne, feijão e temperos (como eles explicam, uma espécie de mocotó sem mondongo), batizado de "caldo pomerano". Também nos casamentos de membros da comunidade, realizados no mesmo salão, caldo e sopa não podem faltar. Na realidade, mocotó e sopa de galinha são pratos recorrentes em outras localidades da região, nas 
festas de comunidades em que existe forte presença de camponeses de origem pomerana.

Caldo e sopa são produtos e produtores de divisões de gênero. Enquanto o primeiro é preparado pelos homens, o segundo fica a cargo das mulheres. Geralmente é um casal bem considerado pela comunidade que fica responsável por essa função, no que é auxiliado por outros homens e mulheres mais novos. No Butiá, nos casamentos e festas comunitárias, já há bastante tempo o preparo desses pratos fica a cargo de Seu Roni e de Dona Lúcia.

Marcel Mauss (2003) observa que as trocas estão na base das alianças que constituem a sociedade. Essas trocas podem ser de bens materiais ou imateriais (serviços, rituais, hospitalidade, etc.) e são de outra natureza que a estritamente utilitária - a troca justifica-se por si mesma e pela aliança que gera, não pela coisa trocada, que representa mais o meio pelo qual a relação é estabelecida. A troca pressupõe, ainda, as obrigações de "dar, receber e retribuir".

É através da feitura do caldo e da sopa que Seu Roni e Dona Lúcia estabelecem uma reciprocidade com o coletivo. Quando são convidados para um casamento, é esse o presente que se espera deem aos noivos. Nas festas da comunidade, tal qual seus pares, doam seu trabalho, além de aportarem a maior parte dos ingredientes a serem usados na preparação dos pratos sob sua responsabilidade.

Essa reciprocidade assume por vezes o sentido mesmo de obrigação. Seu Roni confidencia que, já aos 63 anos, gostaria de parar de preparar o caldo, mas ainda não encontrou alguém que pudesse substituí-lo. Nenhum de seus ajudantes nem de seus filhos se coloca disponível para assumir a obrigação de seguir o preparo do caldo em seu lugar. Eles parecem conhecer bem as consequências de assumir essa responsabilidade e, por isso mesmo, declinam a indicação.

Assim, se as particularidades da família são importantes para entender muito de seu comportamento e de suas escolhas, que conformaram sua trajetória de vida (sobretudo no que diz respeito ao trabalho na agroecologia), a relação com o coletivo (seu pertencimento étnico e religioso, a própria inserção na comunidade luterana e as relações de vizinhança e parentesco) também se faz importante para entender como essa família é.

Como já visto, Ginzburg (2006) define a trajetória de Menocchio analisando, por um lado, suas escolhas individuais (leituras e teorias com que simpatizava) e, por outro, o próprio contexto social e temporal em que estava inserido localmente (a cultura camponesa daquela região e época). Assim como Menocchio, a família interlocutora desta pesquisa apenas pode ser parcialmente definida por aquilo que representa suas diferenças; outra parte advém de sua inserção em uma comunidade e em uma época definidas.

Mesmo que haja divergências entre os membros da comunidade quanto a escolhas e concepções, em suma, mesmo que essa comunidade não seja homogênea - como quem sabe alguns pensassem -, ainda assim não se pode 
atribuir todos os comportamentos a decisões individuais. A vida comunitária tem um papel importante no modo de vida da família Mühlemberg. Contudo, ainda é preciso tornar claro o que entendemos por comunidade.

Para Antônio Candido (1987), o trabalho compartilhado e a participação nas festas religiosas são os dois principais elementos de conformação de uma comunidade rural. Em seu estudo sobre os bairros rurais de São Paulo na década de 1950, o autor mostrou como os mutirões de trabalho e a organização das festas conformavam tais comunidades. Como descreve, para solucionar o problema da mão de obra na realização de determinadas atividades agrícolas que demandavam mais pessoas que aquelas disponíveis no grupo familiar, os vizinhos organizavam-se em mutirões de trabalho. Da mesma forma, as festas religiosas eram organizadas conjuntamente entre os vizinhos, que revezavamse à frente da organização, revezando também o senso de responsabilidade entre os copartícipes. Assim, para o autor, a reciprocidade gerada a partir dos mutirões e das festas constituía-se como elemento de aproximação da vizinhança e conformava a comunidade.

John Comerford define comunidade rural como:

“[...] um grupo concreto delimitado em termos territoriais (a população de uma localidade, distrito, município) e em termos de sua atividade (pessoas que se ocupam de atividades "rurais", ligadas à agricultura e à pecuária), mas, ao mesmo tempo, a expressão sugere que esse grupo se organiza a partir de relações de proximidade e solidariedade, em que sobressaem a importância do parentesco, vizinhança, cooperação no trabalho, coparticipação nas atividades lúdico-religiosas, apontando para valores de harmonia e consenso" (2005: 112).

Comerford alerta para a impossibilidade de pensar uma comunidade enquanto unidade homogênea e aponta as dimensões conflitivas da vida comunitária. Segundo o autor: "vários estudos feitos em comunidades rurais mostram que a solidariedade e a igualdade que caracterizam tais comunidades são indissociáveis de uma dimensão conflitiva, como dois lados de uma mesma moeda" (Comerford 2005: 117). O autor destaca, ainda, a noção de comunidade moral, introduzida pelo antropólogo inglês Frederick George Bailey, que enfatiza a dependência do julgamento recíproco em termos de dados valores morais, com base em determinados códigos comunicativos e meios de circulação de informações e julgamentos morais (como a fofoca). Para Bailey, o conflito seria constitutivo das relações comunitárias.

Em seu próprio estudo, realizado na região da Zona da Mata de Minas Gerais, John Comerford (2004) demonstrou como os conflitos entre membros de uma comunidade e as narrativas desses conflitos fazem parte da sociabilidade camponesa. Apesar do discurso de que "todo mundo se dá bem", os 
conflitos fazem parte da realidade diária; surgem a partir da observação do comportamento dos demais - da vigilância mútua - e das narrativas textuais geradas a partir da observação: a conversa, a crítica, a gozação e a fofoca. Para ele, o conflito diz respeito ao que denomina de "cosmologia prática", centrada na noção de respeito. "Briga-se por tudo o que possa ser visto como provocação, como desrespeito. E, diante do desrespeito, depara-se justamente com a ameaça a uma viga mestra desse universo social: o respeito" (Comerford 2004: 3-4).

As comunidades, assim, definem os pertencimentos: aqueles que pertencem e os outros, que são os de fora. Essas comunidades, contudo, não são fechadas e seus membros ligam-se a outros atores, em outras redes de relações.

Patrícia Pinheiro (2010) mostra como produtores, consumidores e membros de instituições vinculadas à agroecologia, mesmo distanciados fisicamente, acabam constituindo redes de relações em torno da agroecologia. Isso é o que ocorre também com a família de Seu Roni que, ao longo dos anos, estabeleceu relações com instituições ligadas de alguma forma à agroecologia, como o CAPA (Centro de Apoio ao Pequeno Agricultor) e a Embrapa, com outros produtores agroecológicos - muitas vezes a partir da mediação dessas instituições - e com consumidores, principalmente aqueles que, a cada semana, vão à feira, em São Lourenço do Sul.

Embora caiba reconhecer que essas redes são importantes no moldar as convicções e o próprio trabalho da família, não se pode ignorar o papel das relações comunitárias locais - mesmo conflitivas - na conformação de seu modo de vida.

No entanto, mesmo com a existência desses conflitos e diferenças em relação à vizinhança, especialmente no que diz respeito ao trabalho na terra (são produtores ecológicos em meio a fumicultores), a família não pode ser tomada como uma ilha. Tentamos mostrar como a vizinhança e o parentesco, a participação na vida religiosa e nas festas e a própria identidade assumida (pomerana) fazem parte da vida dos Mühlemberg tanto quanto sua vinculação a um modelo de produção agroecológico e como essas práticas e valores são por vezes concorrentes, enquanto que em outras oportunidades reforçam-se mutuamente.

\section{CONSIDERAÇÕES FINAIS}

Ainda que, como buscamos demonstrar neste trabalho, as práticas da família na agroecologia sejam principalmente orientadas por valores associados à saúde, religiosidade e cosmologias, além de serem permeáveis às relações de parentesco e comunitárias, a dimensão econômica não pode ser ignorada. Assim como se dá entre as demais famílias rurais, também o progresso financeiro está na pauta da família Mühlemberg. 
Seu Roni conta que já pensou em desistir inúmeras vezes, mas que suas conviç̧ões o fazem permanecer na agroecologia. Ele comenta que, ainda que não utilize agrotóxicos ou transgênicos ("criações da modernidade"), não deseja trabalhar "como faziam [seus] avós". Considera que o desenvolvimento de tecnologias e sua utilização também são necessários para a agricultura de base ecológica. Já aposentado, almeja reduzir o ritmo de trabalho, até que possa parar totalmente. Afinal, como tem dito, "não durará para sempre".

Nesse contexto, uma questão que se mostra cada vez mais importante para a família pensar seu futuro é o tema da sucessão. O problema da sucessão, efetivamente, está associado à questão da reprodução social das famílias, colocado em todo o universo camponês.

Dos filhos de Seu Roni, Luciano, o "cientista", defende sempre a ideia de permanecer no campo e na agroecologia. Ele diz que não conseguiria acostumar-se na cidade, pois gosta mesmo do meio rural e do contato com a natureza. Ele utiliza a ciência que aprendeu para contribuir para a permanência da família na agroecologia. Ao longo dos anos, Luciano já pensou em algumas alternativas para complementar a renda da família e, desse modo, reduzir a pressão no sentido da retomada de uma prática mais convencional. Entre os experimentos, ele criou uma estufa para a produção de cogumelos shitake e uma máquina para fabricar palitos de churrasquinho com taquara, ambas iniciativas ecológicas. Contudo, por diferentes motivos, nenhuma das alternativas engendradas teve êxito.

Para Moacir, entretanto, casado, trabalhando na propriedade (diferentemente de Luciano), a questão do progresso financeiro parece contar um pouco mais. Como sempre comenta, quer conseguir, através de seu trabalho, prosperar e adquirir bens materiais. Também pensa em começar uma vida nova e melhor com sua esposa, com quem se casou há pouco tempo. Mais de uma vez ele propôs ao pai sair da agroecologia e voltar para a agricultura convencional, mas Seu Roni recusou. Recentemente, influenciado por um antigo membro do grupo de agroecologia do qual Seu Roni fazia parte, passou a cultivar na propriedade o "fumo orgânico". Seu Roni aceitou, por entender que o filho tem o direito de buscar prosperar economicamente.

As aspirações de progresso a que Moacir se refere parecem encontrar paralelo entre seus vizinhos. Por esse motivo, inclusive, muitos aderiram à fumicultura. Como tentamos demonstrar, se, por uma perspectiva técnica e econômica, as produções de fumo e agroecológica se situam bem distanciadas, de outra perspectiva, pensando as relações de vizinhança e de parentesco, os dois modelos produtivos não estão tão distantes assim.

Mais do que isso, entendemos que, embora as escolhas individuais e as relações no interior de uma rede de alimentação ecológica sejam necessárias para definir o trabalho da família na agroecologia, não podemos ignorar a importância da comunidade nesse processo. Pelo contrário, as relações de vizinhança 
e parentesco, bem como a participação nas atividades religiosas e nas festas, são fundamentais para a vivência dessa família e para a constituição de suas práticas e valores, refletindo-se inclusive em seu trabalho na terra.

Suas visões de mundo quanto à relação com a natureza têm um fundo religioso, o mesmo que é partilhado pela comunidade e transmitido pela igreja, mesmo que nem todos levem a prática para o mesmo lado, aderindo à agroecologia, como a família de Seu Roni. Mesmo que, sob vários aspectos, haja divergências entre os membros da comunidade, ainda assim existe um fundo comum. Se quisermos apreender o que motiva os produtores ecológicos, não podemos apenas visualizá-los isoladamente, como ilhas em seus contextos, ou em relação apenas com outros agricultores que adotaram o mesmo sistema. Como Menocchio, a família Mühlemberg pode apenas em parte ser definida por suas especificidades, na medida em que seus valores advêm também desse fundo comum partilhado com sua comunidade.

A análise da trajetória dessa família revela essa intersecção com a comunidade, mas também auxilia a perceber questões mais gerais a partir da observação local. Assim, do mesmo modo que Ginzburg (2006: 10) apontou que "uma investigação que, no início, girava em torno de um indivíduo, sobretudo de um indivíduo aparentemente fora do comum, acabou desembocando numa hipótese geral sobre a cultura popular - e, mais precisamente, sobre a cultura camponesa - da Europa pré-industrial [...]", no presente estudo pretendemos, igualmente, contar uma história particular, sobre uma família particular, mas que, a todo o momento, é perpassada por questões que tangem, além dela própria e de sua comunidade, um contexto mais amplo, referente a modos de vida de colonos da Serra dos Tapes e de um mundo camponês. 


\section{BIBLIOGRAFIA}

BAHIA, Joana, 201 1, O Tiro da Bruxa: Identidade, Magia e Religião na Imigração Alemã. Rio de Janeiro, Garamond.

BOURDIEU, Pierre, 2006, “O camponês e seu corpo", Revista de Sociologia e Política, 26: 83-92.

BRANDÃO, Carlos Rodrigues, 1986, "Povo pobre, deuses ricos", em Carlos Rodrigues Brandão, Os Deuses do Povo: Um Estudo sobre a Religião Popular. São Paulo, Brasiliense, 120 -149 .

CÂNDIDO, Antônio, 1987, Os Parceiros do Rio Bonito: Estudo sobre o Caipira Paulista e a Transformação dos Seus Meios de Vida. São Paulo, Livraria Duas Cidades.

COMERFORD, John, 2004, "Sociabilidade e narrativa em comunidades camponesas (e algumas considerações sobre 'participação')", apresentado na 24. ${ }^{a}$ Reunião Brasileira de Antropologia, Olinda, PE, 12 a 15 de junho.

COMERFORD, John, 2005, “Comunidade rural”, em Márcia Motta (org.), Dicionário da Terra. Rio de Janeiro, Civilização Brasileira, 1 12-120.

COSTA, Jairo Scholl, 1984, “Origens históricas do município de São Lourenço do Sul”, em São Lourenço do Sul: Cem Anos, 1884-1984. São Lourenço do Sul, Prefeitura Municipal de São Lourenço do Sul, 39-77.

FONSECA, Claudia, 2008, "O anonimato e o texto antropológico: dilemas éticos e políticos da etnografia 'em casa'”, Teoria e Cultura, 2 (1): 39-53.

GINZBURG, Carlo, 2006, O Queijo e os Vermes: O Cotidiano e as Idéias de um Moleiro Perseguido pela Inquisição. São Paulo, Companhia das Letras.

LATOUR, Bruno, 1994, Jamais Fomos Modernos: Ensaio de Antropologia Simétrica. Rio de Janeiro, Editora 34.

LEACH, Edmund R., 2004 [1954], Sistemas Políticos da Alta Birmânia: Um Estudo da Estrutura Social Kachin. São Paulo, Edusp.

MALINOWSKI, Bronislaw, 1978 [1922], Os Argonautas do Pacífico Ocidental. São Paulo, Editora Abril.

MAUSS, Marcel, 2003, Ensaio sobre a Dádiva: Forma e Razão da Troca nas Sociedades Arcaicas, Sociologia e Antropologia. São Paulo, Cosac Naify.

MeIHY, José Carlos Sebe Bom, e Fabíola HOLANDA, 2007, História Oral: Como Fazer, como Pensar. São Paulo, Contexto.

MENASCHE, Renata, e Josiane Carine WEDIG, s.d. (no prelo), "Fiestas de familia: parentesco ampliado, ruralidad celebrada”, Gazeta de Antropología.

PINHeiro, Patrícia dos Santos, 2010, Saberes, Plantas e Caldas: A Rede Sociotécnica de Produção Agrícola de Base Ecológica no Sul do Rio Grande do Sul. Porto Alegre, Universidade Federal do Rio Grande do Sul, dissertação de mestrado em Desenvolvimento Rural.

SALAMONI, Giancarla, e Carmen WASKIEVICZ, 2013, "Serra dos Tapes: espaço, sociedade e natureza", Tessituras, 1 (1): 73-100.

WOORTMANN, Klaas, 1990, “'Com parente não se neguceia’: o campesinato como ordem moral”, Anuário Antropológico, 87: 11-73.

WOORTMANN, Ellen, e Klaas WOORTMANN, 1997, O Trabalho da Terra: A Lógica e a Simbólica da Lavoura Camponesa. Brasília, Editora Universidade de Brasília. 